\title{
ANALISA PENGARUH DATA RATE PADA MANET DENGAN MENGGUNAKAN ROUTING PROTOCOL AODV (REAKTIF)
}

\author{
Anisa Widayanti ${ }^{1}$, I Gusti Agung Komang Diafari Djuni ${ }^{2}$, N.M.A.E Dewi Wirastuti ${ }^{3}$ \\ Program Studi Teknik Elektro, Fakultas Teknik, Universitas Udayana \\ Email: untukanisa@gmail.com ${ }^{1}$, igakdiafari@ee.unud.ac.id ${ }^{2}$, dewi.wirastuti@ee.unud.ac.id ${ }^{3}$
}

\begin{abstract}
ABSTRAK
Mobile Ad hoc Network (MANET) merupakan jaringan wireless mobile node yang bersifat dinamis, tanpa menggunakan infrastruktur jaringan seperti keterbatasan daya (karena menggunakan baterai), Mobilitas setiap node yang mampu bergerak ke segala arah, dan otonomi setiap node dalam menentukan sendiri rute untuk meneruskan paket datanya. Maka pada penelitian ini akan melihat kinerja MANET pada WLAN IEEE $802.11 \mathrm{~g}$ dengan data rate yang berbeda dari sebuah routing protocol AODV. Simulasi ini mengamati perubahan data rate mulai dari 1, 2, 5 Mbps, dengan menggunakan WLAN $802.11 \mathrm{~g}$. Untuk parameter yang digunakan pada data rate mulai dari 1, 2, 5, Mbps dengan menggunakan WLAN $802.11 \mathrm{~g}$ mendapatkan nilai Paket Loss pada data rate 5 Mbps sebesar 0,98\%, nilai rata-rata Throughput paling tinggi dihasilkan pada data rate 1 Mbps sebesar 313.715 bps, dan Delay untuk data rate 5 Mbps sebesar 0.0008 second.
\end{abstract}

Kata kunci: AODV, FTP, MANET, WLAN

\section{ABSTRACT}

Mobile Ad hoc Network (MANET) is a dynamic wireless mobile node network, without using network infrastructure such as limited power (because it uses batteries). Mobility of each node that is able to move in all directions, and autonomy of each node in determining its own route to forward the data plan. Therefore, in this study we will see the performance of MANET on IEEE $802.11 \mathrm{~g}$ WLAN with a data rate that is different from an AODV routing protocol. This simulation observes changes in data rates ranging from 1, $2.5 \mathrm{Mbps}$, using WLAN $802.11 \mathrm{~g}$. For parameters used in the data rate starting from 1, 2, 5, Mbps using WLAN $802.11 \mathrm{~g}$ obtained the Package Loss value at a data rate of $5 \mathrm{Mbps}$ by $0.98 \%$, the highest value of the highest throughput was generated at a data rate of 1 Mbps of 313,715 bps, and the delay for the data rate of 5 Mbps was 0.0008 second.

\section{Keywords: AODV, FTP, MANET, WLAN}

\section{PENDAHULUAN}

Kebutuhan akan teknologi terutama internet saat ini seakan menjadi kebutuhan primer bagi masyarakat. Teknologi yang cukup diminati dan berkembang pesat adalah jaringan nirkabel (wireless), yang mana lebih banyak digunakan dibandingkan jaringan berkabel. Sehingga muncul suatu teknologi pengembangan jaringan nirkabel yaitu tipe jaringan Ad-Hoc. Jaringan ad hoc adalah jaringan yang dapat berdiri dan bekerja tanpa harus menggunakan kabel dan infrastruktur tanpa perantara (access point). [3]

Pengembangan dari teknologi jaringan ad hoc yaitu Mobile $\mathrm{Ad} H \mathrm{Hoc}$
Network (MANET), yaitu kumpulan dari beberapa wireless mobile node yang di setup secara dinamis kapan saja dan dimana saja tanpa menggunakan infrastruktur dan setiap node bergerak secara bebas sehingga mengakibatkan perubahan topologi secara cepat.[1] Pada jaringan $A d$ Hoc, MANET memiliki beberapa model protokol routing yaitu proaktif dan reaktif, routing rekatif yaitu tabel routing dibentuk jika ada permintaan pembuatan route link baru atau perubahan link, contohnya $A d$ hoc On Demand Distance Routing (AODV), protokol hop-by-hop dimana node-node menggunakan tabel routing untuk 
menentukan hop berikutnya di dalam perjalanan menuju tujuan.

Pada jaringan WLAN biasanya menggunakan standart IEEE 802.11, standart yang digunakan pada penelitian ini IEEE 802.11g, standar 802.11g memiliki kelebihan dalam hal kompatibilitas, ada juga perangkat standart $802.11 \mathrm{~g}$ pada saat mencoba berpindah ke jaringan 802.11b ataupun sebaliknya, bisa saja akan memunculkan masalah baru. $\mathrm{Hal}$ itu disebabkan oleh karena adanya penggunaan frekuensi $2,4 \mathrm{~Hz}$ yang kompatibel dengan standard 802.11b. penggunaan modulasi OFDM diperlukan pada perangkat standard $802.11 \mathrm{~g}$ dengan tujuan untuk memperoleh kecepatan transfer data berkecepatan tinggi. [7]

Adapun kinerja MANET pada WLAN IEEE 802.11 g tersebut dilakukan dengan menganalisa pengaruh data rates pada MANET dengan data rate yang berbeda menggunakan routing protocol AODV (reaktif) dengan cara melihat perubahan data rates yang berbeda-beda.

\section{KAJIAN PUSTAKA \\ 2.1 WLAN (Wireless Local Area Network) \\ Kebutuhan akan jaringan Wireless} Local Area Network (WLAN) lebih diminati karena pada pada jaringan ini menggunakan gelombang radio sebagai alat atau media transmisi data. Pada umumnya menggunakan Frekuensi 2,4Ghz dan 5,8Ghz. Jaringan WLAN ini secara internasional termasuk di wilayah licensce exempt (bebas lisensi) sehingga dapat digunakan oleh public (frequency sharing).

\subsection{MANET}

Mobile Adhoc Network (MANET) terdiri dari wireless mobile node, dapat diset up secara dinamis tanpa mengunaka jaringan insfratuktur. Mengalami perubahan topologi dengan sangat cepat karena di dalam MANET memiliki node-node yan bergerak secara bebas.

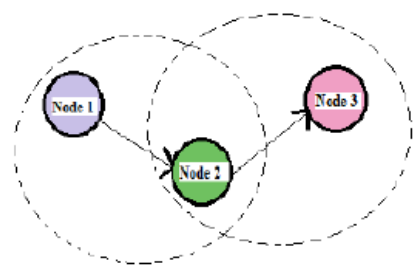

Gambar 1 Contoh MANET
Terdapat berbagai jenis protokol routing untuk MANET yang secara keseluruhan dapat dibagi menjadi beberapa kelompok, antara lain Proactive Routing yaitu mengelola daftar tujuan dan rute terbaru masing-masing dengan cara mendistribusikan routing table ke seluruh jaringan, untuk Reactive Routing sendiri yaitu mencari rute (on demand) dengan cara membanjiri jaringan dengan paket router request.

\section{$2.3 \quad$ AODV}

Merupakan protokol hop-by-hop dimana node-node antara menggunakan tabel routing mereka untuk menentukan hop berikutnya di dalam perjalanan menuju tujuan. pada setiap node dapat menjaga timer-based start sesuai dengan penggunaan table routing. Pada proses route discovery node asal akan melakukan broadcast ke route request (RREQ) packets menggunkan nomor sequence tujuan, node tujuan akan menerima paket RREQ, node akan memeriksa nomor sequence tujuan dan ketika paket tiba nomor sequence akan memeriksa nomor tujuan RREQ yang dikirim. Node tujuan akan membalas paket RREQ menggunakan route reply (RREP) paket dengn tujuan memastikan paket bersifat baru.

\section{$2.4 \quad F T P$}

File Transfer Protocol (FTP) merupakan jaringan atau network yang menyedikan file untuk saling tukar menukar informasi menggunakan koneksi TPC dengan port 21. Terdapat dua komponen penting yang berperan didalam FTP yaitu FTP server dan FTP client.

Pada FTP server berfungsi untuk memberikan layanan pertukaran informasi atau file apabila FTP client meminta, sedangkan untuk FTP client yaitu meminta koneksi pada FTP server agar dapat bertukar informasi.

\section{METODOLOGI PENELITIAN}

Diagram alir diperlukan untuk membantu poses pembuatan sistem. Mulai dari study literature, perancangan perangkat keras, perancangan perangkat lunak, dan terakhir. Pada gambar 2 akan menunjukan alur analisa data dari scenario 


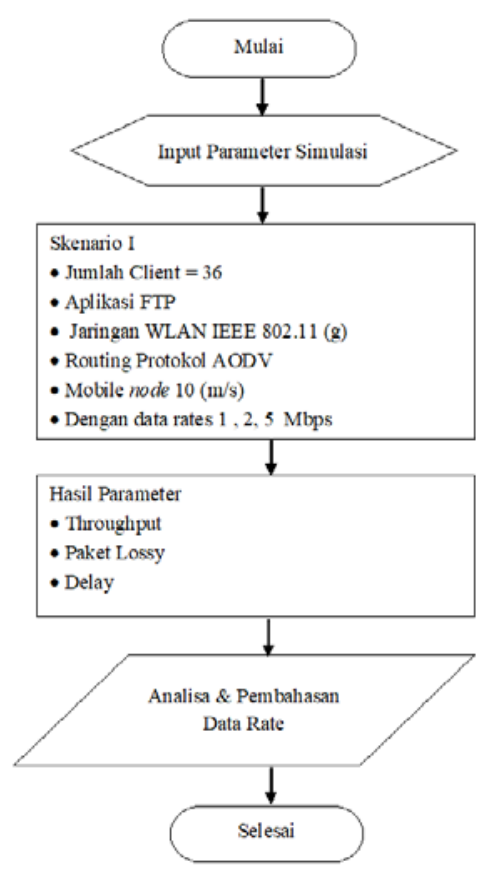

Gambar 2 Diagram Scenario

\subsection{HASIL}

Pada penelitian ini menggunakan Opnet Modeler sebagai simulator pendukung teknologi MANET dan memberikan pilihan statistik layanan aplikasi, serta menampilkan statistik QoS WLAN seperti Throughput, Packet Loss dan Delay serta mengamati perubahan data rates dengan WLAN tipe $g$ yang berguna untuk mendukung analisis dalam penelitian. Pada tabel 1 menunjukan parameter simulasi yang digunakan pada scenario ini.

Tabel 1 Parameter Simulasi

\begin{tabular}{|l|l|}
\hline \multicolumn{1}{|c|}{ Statistic } & \multicolumn{1}{c|}{ Value } \\
\hline $\begin{array}{l}\text { WLAN Physical } \\
\text { Characteristic }\end{array}$ & IEEE 802.11g \\
\hline $\begin{array}{l}\text { Packet Reception- } \\
\text { Power Threshold }\end{array}$ & $-95 \mathrm{dBm}$ \\
\hline Data rate & $1,2,5 \mathrm{Mbps}$ \\
\hline Transmit Power & $0,005 \mathrm{~W}$ \\
\hline Buffer Size & 256000 \\
\hline Simulator & OPNET 14.5 \\
\hline Routing Protocols & AODV \\
\hline Scenario Size & $5 \mathrm{~km} \times 5 \mathrm{~km}$ \\
\hline Simulation Time & $30 \mathrm{Minutes}$ \\
\hline No. of nodes & $36($ Mobile) \\
\hline Speed & $10 \mathrm{~m} / \mathrm{s}$ \\
\hline
\end{tabular}

\subsubsection{Simulasi perubahan data rate pada MANET}

Dalam simulasi ini menggunakan node pada kondisi bergerak (mobile), dengan beberapa variasi data rate $1,2,5$ Mbps dan 36 node, serta menggunakan Application Config, Profile, Definition, Attributes Mobility, Server dengan Aplikasi FTP, ditunjukan seperti gambar pada 3

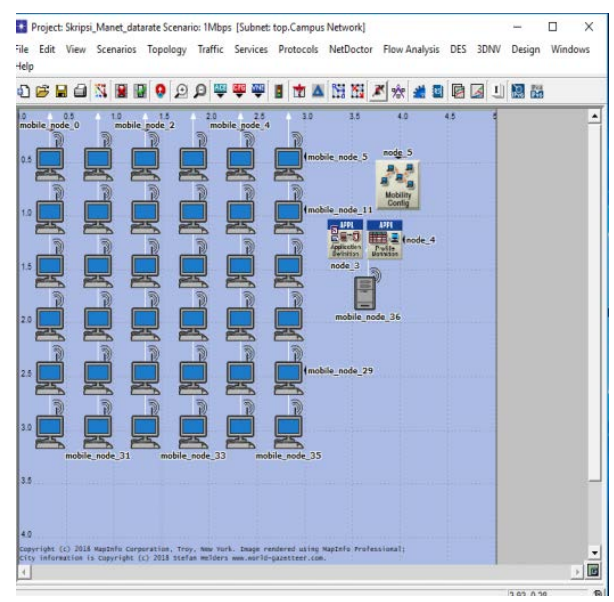

Gambar 3 Pemodelan Simulasi

\subsection{PEMBAHASAN \\ 4.2.1 Parameter Router Discovery \\ Time}

Hasil parameter dari Router Time Discovery yang ditampilkan merupakan hasil running dari simulasi ini, dengan data rate yang berbeda. Pada gambar 4 menunjukkan hasil grafik dari Router Discovery Time.

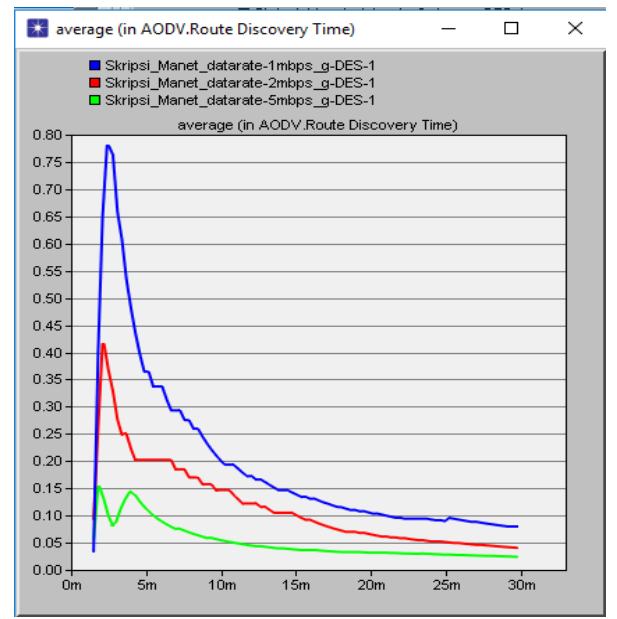

Gambar 4 grafik Router Discovery Time

Dilihat dari grafik pada 1 menit menunjukan kenaikan yang sangat signifikan, akan tetapi pada saat 4 menit 
grafik menunjukan penurunan, sehingga pada 5 menit berikutnya grafik stabil sampai menit ke 30. Dapat dilihat hasil dari nilai rata-rata Route Discovery Time pada tabel 2.

Tabel 2 Nilai Rata-rata Route Discovery Time Data Rate dari 1, 2, 5 Mbps

\begin{tabular}{|l|l|}
\hline Data rate & $\begin{array}{l}\text { Rata-rata Packet Route } \\
\text { Discovery Time (sec) }\end{array}$ \\
\hline $1 \mathrm{Mbps}$ & 0.1956 \\
\hline $2 \mathrm{Mbps}$ & 0.1166 \\
\hline $5 \mathrm{Mbps}$ & 0.0512 \\
\hline
\end{tabular}

Dilihat dari keseluruhan simulasi yang di hasilkan data rate untuk rata-rata yang dihasilkan dari simulasi tersebut pada data rate 5 Mbps menghasilkan nilai ratarata paling rendah diantara data rate lainya yaitu 0.0512 Sec.

\subsubsection{Parameter FTP upload dan download \\ Pada grafik dibawah ini} menunjukan hasil dari running FTP Upload dan Downlod. Gambar grafik dari FTP Upload bisa dilihat pada gambar 5 .

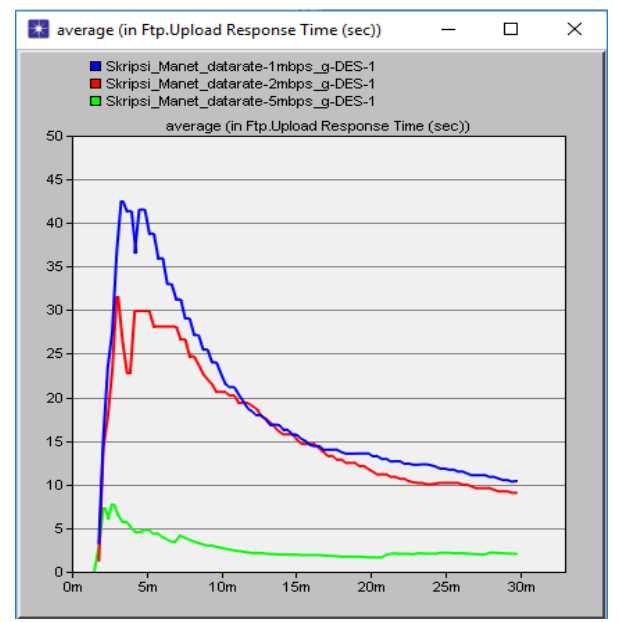

Gambar 5 grafik Upload

Selisih yang dihasilkan dari FTP Upload jika dilihat dari grafik, untuk data rate 5 Mbps memiliki selisih waktu paling kecil dari yang lainya, dapat dilihat dari hasil nilai rata-rata pada tabel 3 .
Tabel 3 Nilai Rata-rata dari FTP Upload Data Rate dari 1, 2, 5 Mbps

\begin{tabular}{|l|l|}
\hline \multicolumn{1}{|c|}{ Data rate } & $\begin{array}{l}\text { Rata-rata FTP Upload } \\
\text { (sec) }\end{array}$ \\
\hline $1 \mathrm{Mbps}$ & 18.99 \\
\hline $2 \mathrm{Mbps}$ & 16.31 \\
\hline $5 \mathrm{Mbps}$ & 2.70 \\
\hline
\end{tabular}

Jika dilihat dari grafik dan rata-rata dari FTP Upload pada saat data rate 5 Mbps memerlukan waktu lebih sedikit yaitu $2.70 \mathrm{sec}$ pada saat melakukan upload suatu file. sedangkan untuk grafik dari FTP Download ditujukan pada gambar 6 .

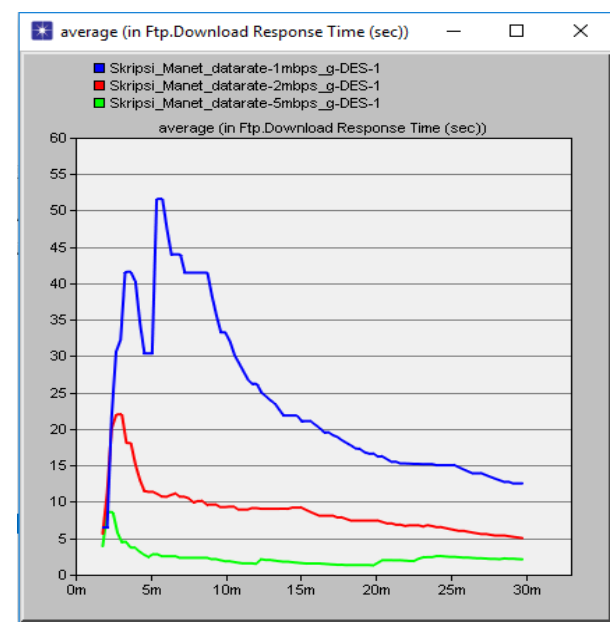

Gambar 6 grafik Download

Grafik dari FTP Download pada data rate $1 \mathrm{Mbps}$ memerlukan waktu cukup lama saat pengunduhan suatu file sebesar 23.64 Sec, dapat dibuktikan dari tabel 4.

Tabel 4 Nilai Rata-rata dari FTP Download Data Rate dari 1, 2, 5 Mbps

\begin{tabular}{|l|l|}
\hline \multicolumn{1}{|c|}{ Data rate } & $\begin{array}{l}\text { Rata-rata FTP } \\
\text { Download (sec) }\end{array}$ \\
\hline $1 \mathrm{Mbps}$ & 23.64 \\
\hline $2 \mathrm{Mbps}$ & 8.81 \\
\hline $5 \mathrm{Mbps}$ & 2.30 \\
\hline
\end{tabular}

\subsubsection{Parameter Packet Loss}

Parameter Packet Loss untuk simulasi didapatkan dengan mengamati hasil running parameter FTP traffic sent dan FTP traffic received. Grafik dari FTP traffic sent dapat dilihat dari gambar 7 . 


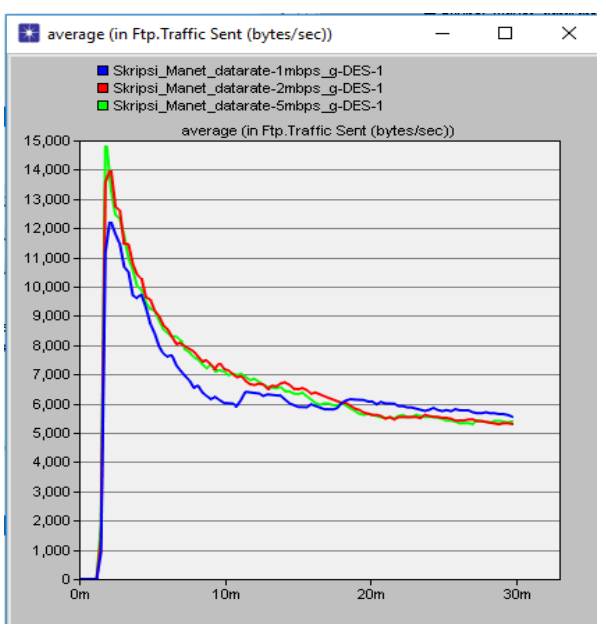

Gambar 7 grafik Traffic Sent

Grafik menunjukan kenaikan pada saat 1 menit, akan tetapi pada saat menit ke 5 grafik mengalami penurunan, dan pada menit ke 10 sampai ke 30 grafik menunjukan kestabilan. Untuk grafik Traffic Received ditunjukan pada gambar 8

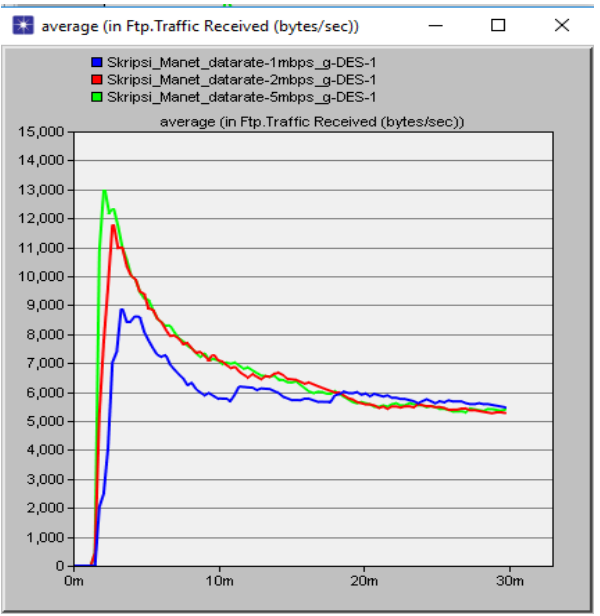

Gambar 8 grafik Traffic Received

Hasil dari paket Loss yang didapat pada simulasi ini dapat dilihat dari tabel 5

Tabel 5 Nilai Rata-rata dari paket loss Data Rate dari 1, 2, 5 Mbps

\begin{tabular}{|l|l|l|l|}
\hline Data rate & $\begin{array}{c}\text { Trafic } \\
\text { sent } \\
\text { (byte/sec) }\end{array}$ & $\begin{array}{c}\text { Trafic } \\
\text { received } \\
\text { (byte/sec) }\end{array}$ & $\begin{array}{c}\text { Packet } \\
\text { Loss } \\
(\%)\end{array}$ \\
\hline $1 \mathrm{Mbps}$ & 6.256 & 5.686 & $9,1 \%$ \\
\hline $2 \mathrm{Mbps}$ & 6.554 & 6.280 & $4,2 \%$ \\
\hline $5 \mathrm{Mbps}$ & 6.497 & 6.433 & $0,98 \%$ \\
\hline
\end{tabular}

Dilihat dari hasil parameter paket Loss pada data rate 1 Mbps mengalami paket loss paling besar diantara dari ketiga data rate. Untuk data rate 5 Mbps mengalami paket Loss dengan persentasi paling rendah yaitu $0,98 \%$.

\subsubsection{Parameter Throughput}

Hasil parameter Throughput yang ditampilkan merupakan hasil running global statistic dengan hasil berupa grafik dan nilai rata-rata (average). Hasil running dari parameter Throughput dapat dilihat pada gambar 9.

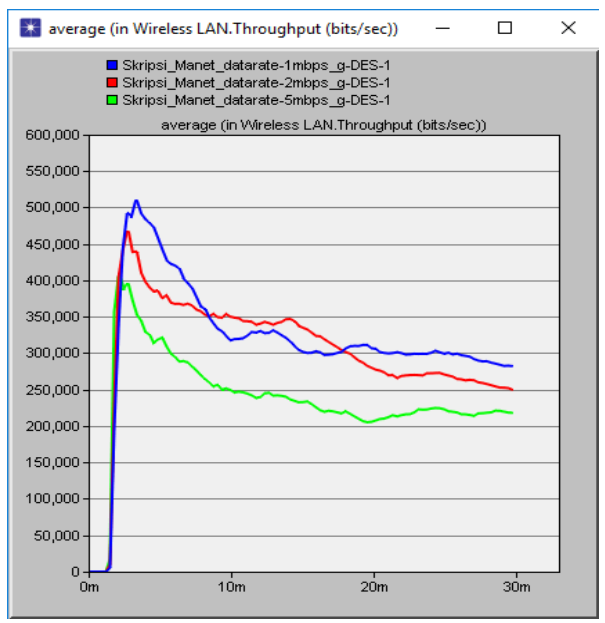

Gambar 9 grafik Throughput

Jika dilihat dari grafik pada data rate 5 Mbps menunjukan nilai rata-rata paling rendah dibandingkan dengan grafik data rate lainya. Bisa dibuktikan dari hasil rata-rata pada tabel 6 .

Tabel 6 Nilai Rata-rata dari Parameter Throughput Data Rate dari 1, 2, 5 Mbps

\begin{tabular}{|l|l|}
\hline \multicolumn{1}{|c|}{ Data rate } & $\begin{array}{l}\text { Rata-rata Throghput } \\
\text { (bits/sec) }\end{array}$ \\
\hline $1 \mathrm{Mbps}$ & 313.715 \\
\hline $2 \mathrm{Mbps}$ & 300.355 \\
\hline $5 \mathrm{Mbps}$ & 234.057 \\
\hline
\end{tabular}

Secara keseluruhan simulasi yang di hasilkan data rate mulai dari 1, 2, 5 Mbps dapat dilihat bahwa semakin besar data ratenya maka rata-rata Throghput semakin kecil.

\subsubsection{Parameter Delay}

Hasil Running dari parameter delay merupakan hasil running global statistic, grafik dari delay dapat dilihat pada gambar 10. 


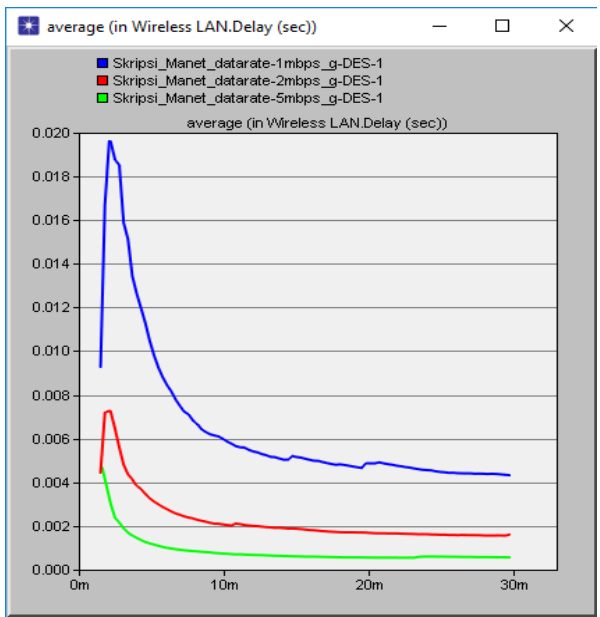

Gambar 10 grafik Delay

Pada grafik 1 Mbps menunjukan kenaikan pada menit ke 1 akan tetapi pada menit ke 5 grafik mengalami penurunan hingga menit ke 30 grafik yang dihasilkan stabil. Bisa dibuktikan dari tabel 7 untuk rata-rata yang dihasilkan dari grafik delay.

Tabel 7 Nilai Rata-rata dari Delay Data Rate dari 1, 2, 5 Mbps

\begin{tabular}{|l|l|}
\hline Data rate & Rata-rata Delay $(\mathrm{sec})$ \\
\hline $1 \mathrm{Mbps}$ & 0.0065 \\
\hline $2 \mathrm{Mbps}$ & 0.0022 \\
\hline $5 \mathrm{Mbps}$ & 0.0008 \\
\hline
\end{tabular}

Secara keseluruhan simulasi yang di hasilkan data rate mulai dari 1, 2, 5 Mbps dapat dilihat bahwa semakin besar data ratenya maka rata-rata dari delay semakin kecil, karena semakin besar data rate maka beban delay pada scenario yang diujikan akan semakin mengurangi proses pengiriman data yang dikirimkan.

\section{Simpulan}

Simpulan yang diambil berdasarkan hasil pengujian untuk pengaruh dari perubahan data rate terhadap QOS pada Paket Loss, Throghput dan Delay yaitu semakin besar perubahan data rate maka grafik atau rata-rata yang dihasilkan akan menurun. Untuk hasil yang didapat dari simulasi dengan perubahan data rate atau penambahan data rate pada parameter Paket Loss dengan menggunakan data rate 5 Mbps yaitu sebesar 0,98 \%, untuk Throghput dengan menggunakan data rate $5 \mathrm{Mbps}$ rata-rata sebesar 234.057 bits/sec dan untuk Delay yang didapat yaitu 0.0008 sec dengan menggunakan data rate $5 \mathrm{Mbps}$.

\section{DAFTAR PUSTAKA}

[1] Aarti, D. S dan Tyagi, Study Of MANET : Characteristic, Challengen, Aplication and Securty Attacks, International Journal Of Advanced Research In Computer Sclence and Software Engineering 3 (5) : 252-257, 2013

[2] Agus Virgono dkk "Analisa Pengaruh Besar Area Hotspot Dan Interferensi Pada Wlan IEEE 802.11b" Departemen Teknik Elektro, Institut Teknologi Telkom Vol. 14, No. 1 Juni 2009

[3] Beny Benardi, "Analisa Unjuk Kerja Jaringan Nirkabel Ad Hoc Dalam Beberapa Situasi Yang Berbeda Ditinjau Dari Sudut Pandang Routing", Universitas Mercu Buana, Jakarta, 2009

[4] Deepika Madan, Ms. Jyoti, Kuldeep Vats "Performance Evaluation of WLAN network based TORA protocol using OFDM (802.11a) and Extended rate PHY (802.11g)", IJSRM volume 4 issue 3 March 2016 www.ijsrm.in, Haryana india

[5] H.S.Mewara, Mukesh Kumar Saini “ Performance Analysis of Access point for IEEE802.11g Wireless LAN Using Opnet Simulator", International Journal of Advanced Engineering Research and Science Vol-1, Issue-1, pp 2349-6495, June 2014

[6] Khusnul, 2012 Jaringan Komputer, http;//khusnulsapcom.blogspot.co.id Diakses pada 11 mei 2017

[7] Manurung, Naemah Mubarakah "Analisis Link Budget Untuk Koneksi Radio Wireless Local Area Network (Wlan) 802.11b Dengan Menggunakan Simulasi Radio Mobile (Studi Kasus Pada Jalan Kartini Siantar-Ambarisan)" Departement Teknik Elektro, Universitas Sumatera Utara (USU) Vol. 7 No. 2/Mei 2014

[8] Thakore Mitesh " Performance Analysis of AODV and OLSR Routing Protocol with Different Topologies" International Journal of Science and Research (IJSR), Volume 2 Issue 1, January 2013 www.ijsr.net, India 